\title{
Methods to decrease the influence of the vehicles' service and repair system on the environment
}

\author{
Irina Makarova ${ }^{1}$, Vadim Mavrin ${ }^{1}$, Larisa Gabsalikhova ${ }^{1}$ and Nikolaj Gorjaev ${ }^{2}$ \\ ${ }^{1}$ Kazan Federal University, 423812 Naberezhnye Chelny, Russia \\ ${ }^{2}$ South Ural State University, 454080 Chelyabinsk, Russia
}

\begin{abstract}
Article notes that vehicle maintenance and repair system have a significant negative impact on the environment. To reduce it, dealers must develop and implement an effective environmental management system. Identification of environmental aspects, as well as works and operations related to these aspects were performed. Model's algorithm of the territorial accommodation of vehicle's dealers is presented. This model will allow to find a balance between the vehicle's service system efficiency indicators of the, the costs for owners to delivery of vehicles, waiting in the queue and maintenance and the impact on the environment.
\end{abstract}

\section{Introduction}

In the Russian Federation, the problem of the deteriorating environmental situation is very acute for today. So, being on the twelfth place in the world in terms of GDP, Russia is one of the largest pollutants into the atmosphere, trailing only China, the USA and India in this indicator $[1,2]$. At the same time, the contribution of road transport to air pollution is about $45 \%$ of the country's emissions of pollutants, and its share increases every year $[3,4]$.

\section{Material and methods}

At all stages of the life cycle of a motor vehicle, emissions of pollutants into the environment occur (Fig. 1) [5]. In the context of tightening legislation, vehicle manufacturers pay significant attention to reducing emissions of pollutants at all stages of vehicle production. Manufacturers implement the environmental management system (EMS), improve the fuel and environmental parameters of their vehicles [6]. However, the process of maintaining vehicles in a good technically condition as part of their life cycle is not paid enough attention in terms of impact on the environment. The production and technical base of the vehicle dealers, designed for maintenance and repair works, poses significant threats in terms of environmental safety. So, the contribution of stationary sources, which are on the balance of vehicle service centers, makes from 5 to $20 \%$ of total emissions of pollutants into the atmosphere of cities $[7,8]$.

\footnotetext{
* Corresponding author: kamIVM@mail.ru
} 
Reduction of the negative impact of the vehicle dealers on the environment is possible when creating an efficiently functioning environmental management system at enterprises that meets the ISO 14000 series of standards. The process of development and implementation of EMS and certification of its activities under the ISO 14001 standard is long and costly. However, it is in the interests of vehicle manufacturers to assist dealers in the creation of EMS. They can act as initiators, investors and consultants in the development and implementation of EMS at dealer and service centers. Then the manufacturers of vehicles will be able to say that the cars they produce are really environmentally safe at all stages of the life cycle $[9,10]$. The ecological safety of an organization is understood to mean its environmental impact, which is within the limits of norms.

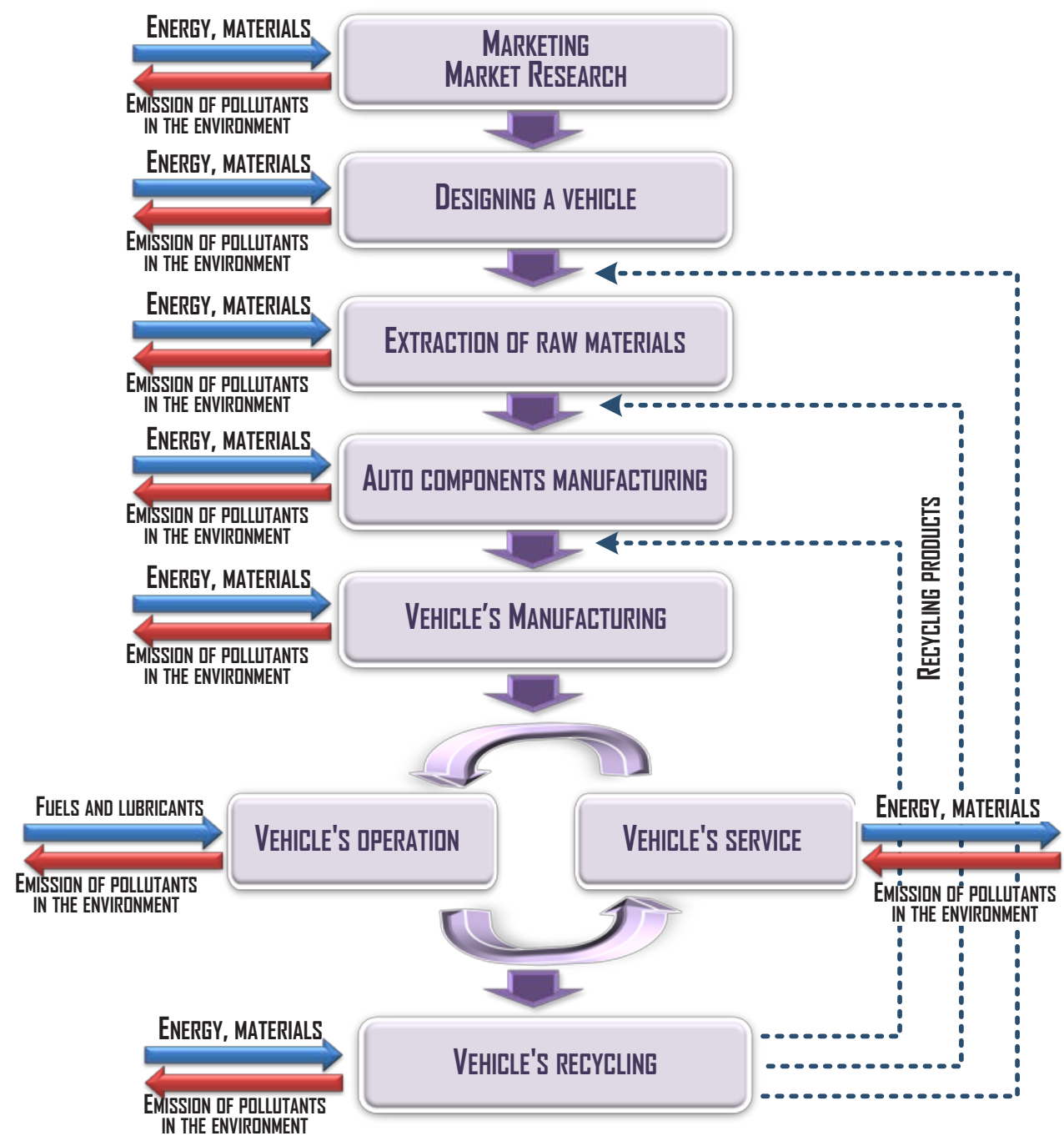

Fig. 1. Block diagram of the vehicle's life cycle.

To determine and comply with such norms, the vehicle dealer should establish targeted environmental indicators that should be based on the knowledge of the identified environmental aspects of the company (elements of an organization's activities or products or services that interact or can interact with the environment) and the negative environmental impacts associated with the activities or services of the vehicle dealer. Identification of 
environmental aspects is an ongoing process that identifies the past, present and possible (positive or negative) impact of the vehicle dealer activities on the environment. Identification of environmental aspects is carried out according to the algorithm presented in Fig. 2. The main environmental aspects of the vehicle dealer are presented in Table 1 [11, 12].

Table 1. Ecological aspects of a vehicle dealer.

\begin{tabular}{|c|c|c|c|c|c|}
\hline № & Operations & $\begin{array}{c}\text { Environmental } \\
\text { aspect }\end{array}$ & Issue factor & $\begin{array}{l}\text { Main polluting } \\
\text { substances }\end{array}$ & $\begin{array}{l}\text { Class of } \\
\text { hazard }\end{array}$ \\
\hline \multirow{5}{*}{1} & \multirow{5}{*}{ Vehicle Wash } & \multirow{3}{*}{ Discharges } & \multirow{3}{*}{ Wastewater } & Surface active agents & \multirow{3}{*}{4} \\
\hline & & & & Suspended substances & \\
\hline & & & & Petroleum products & \\
\hline & & \multirow{2}{*}{ Waste } & \multirow{2}{*}{$\begin{array}{l}\text { Sediment from the } \\
\text { wash }\end{array}$} & Petroleum products & \multirow{2}{*}{-4} \\
\hline & & & & Mechanical impurities & \\
\hline \multirow{5}{*}{2} & \multirow{5}{*}{$\begin{array}{l}\text { Engine } \\
\text { diagnostics }\end{array}$} & \multirow{5}{*}{ Emissions } & \multirow{5}{*}{ Traffic fumes } & $\mathrm{CO}$ & 4 \\
\hline & & & & $\mathrm{NO}_{\mathrm{X}}$ & 2,3 \\
\hline & & & & $\mathrm{SO}_{2}$ & 3 \\
\hline & & & & $\mathrm{C}_{X} \mathrm{H}_{Y}$ & $2-4$ \\
\hline & & & & Carbon & 3 \\
\hline \multirow{4}{*}{3} & \multirow{4}{*}{ Oil change } & \multirow{4}{*}{ Waste } & Oil filters & $\begin{array}{l}\text { Petroleum products, rubber, } \\
\text { steel, paper }\end{array}$ & 3 \\
\hline & & & Used engine oil & $\begin{array}{l}\mathrm{CXH}_{\mathrm{Y}}, \mathrm{S}, \text { mechanical } \\
\text { impurities }\end{array}$ & 3 \\
\hline & & & Used gear oil & $\begin{array}{l}\mathrm{C}_{X} \mathrm{H}_{Y}, \mathrm{~S}, \text { mechanical } \\
\text { impurities }\end{array}$ & 3 \\
\hline & & & Oily wiping rags & $\mathrm{CxHY}_{\mathrm{X}}$, cotton cloth & 3 \\
\hline \multirow{4}{*}{4} & \multirow{4}{*}{$\begin{array}{l}\text { Replacement } \\
\text { and repair of } \\
\text { parts, } \\
\text { assemblies } \\
\text { and units }\end{array}$} & \multirow{4}{*}{ Waste } & \multirow{4}{*}{ Metals, Package } & $\begin{array}{l}\text { Scrap ferrous and non- } \\
\text { ferrous metals }\end{array}$ & 4 \\
\hline & & & & $\mathrm{C}_{\mathrm{X}} \mathrm{H}_{\mathrm{Y}}$, cotton cloth & 3 \\
\hline & & & & Waste plastic materials & - \\
\hline & & & & Wastepaper & - \\
\hline \multirow{7}{*}{5} & \multirow{7}{*}{ Tire repair } & Waste & $\begin{array}{l}\text { Worn tires and } \\
\text { vehicle cameras, } \\
\text { waste rubber } \\
\text { materials }\end{array}$ & $\begin{array}{l}\text { Rubber, carbon black, metal } \\
\text { wire, } \mathrm{S}\end{array}$ & 4 \\
\hline & & \multirow{2}{*}{ Discharges } & \multirow{2}{*}{ Wastewater } & Petroleum products & 3 \\
\hline & & & & Suspendeds ubstances & 3 \\
\hline & & \multirow{4}{*}{ Emissions } & \multirow{4}{*}{$\begin{array}{l}\text { Dust, evaporation of } \\
\text { pollutants }\end{array}$} & Benzine & 4 \\
\hline & & & & Sulphurousanhydride & 3 \\
\hline & & & & Divinyl & 4 \\
\hline & & & & Isoprene & 3 \\
\hline \multirow{7}{*}{6} & \multirow{7}{*}{$\begin{array}{l}\text { Welding and } \\
\text { soldering }\end{array}$} & \multirow{7}{*}{ Emissions } & & Oxide of iron & 3 \\
\hline & & & & $\begin{array}{l}\text { Manganese and its } \\
\text { compounds }\end{array}$ & 2 \\
\hline & & & pollutants during & Dust & 3 \\
\hline & & & soldering and & Hydrogen fluoride & 2 \\
\hline & & & & Tin oxides & 3 \\
\hline & & & & Nickel compounds & 2 \\
\hline & & & & Lead compounds & 1 \\
\hline & & & & Suspended substances & 3 \\
\hline 7 & bodyworks & Emissions & $\begin{array}{l}\text { Sorvent vapors and } \\
\text { paint spray }\end{array}$ & Acetone & 4 \\
\hline & & & & Toluene & 3 \\
\hline
\end{tabular}




\begin{tabular}{|c|c|c|c|c|c|}
\hline № & Operations & $\begin{array}{c}\text { Environmental } \\
\text { aspect }\end{array}$ & Issue factor & $\begin{array}{l}\text { Main polluting } \\
\text { substances }\end{array}$ & $\begin{array}{l}\text { Class of } \\
\text { hazard }\end{array}$ \\
\hline & & & & xylol & 3 \\
\hline & & & & Butylspirit & 3 \\
\hline & & & & Isobutylspirit & 4 \\
\hline & & & & Ethylacetate & 4 \\
\hline & & & & Butylacetate & 4 \\
\hline & & & & Benzine & 4 \\
\hline \multirow{5}{*}{8} & \multirow{5}{*}{$\begin{array}{l}\text { Charging and } \\
\text { repair of } \\
\text { batteries }\end{array}$} & \multirow{3}{*}{ Emissions } & \multirow{3}{*}{$\begin{array}{l}\text { Evaporation of } \\
\text { pollutants }\end{array}$} & $\mathrm{H}_{2} \mathrm{SO}_{4}$ & 2 \\
\hline & & & & Lead compounds & 1 \\
\hline & & & & Oily mist & - \\
\hline & & & Lead accumulators & Lead, plastic, S, antimony & 3 \\
\hline & & Waste & Sulfuric acid & $\mathrm{H}_{2} \mathrm{SO}_{4}$, other sulphates & 2 \\
\hline \multirow{2}{*}{9} & \multirow{2}{*}{$\begin{array}{l}\text { Cleaning of } \\
\text { parts, } \\
\text { components } \\
\text { and units }\end{array}$} & Discharges & Wastewater & $\begin{array}{l}\text { Suspended substances, oil } \\
\text { products, surfactants }\end{array}$ & 3 \\
\hline & & Emissions & $\begin{array}{l}\text { Evaporation of } \\
\text { pollutants }\end{array}$ & Sodium hydroxide, soda ash & 3 \\
\hline 10 & $\begin{array}{l}\text { Replacement } \\
\text { of technical } \\
\text { fluids }\end{array}$ & Discharges & Wastewater & Brake fluid, antifreeze & 4 \\
\hline
\end{tabular}

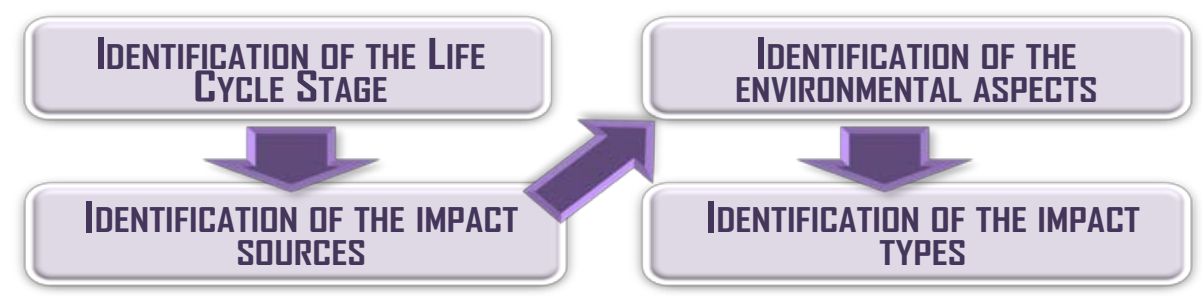

Fig. 2. Sequence of identification of environmental aspects.

The ecological significance of environmental aspects should be assessed taking into account the mass and content of pollutants in emissions and discharges, the maximum allowable concentrations of pollutants and the class of hazard of pollutants. Further, it is necessary to identify the operations and activities that are associated with the identified environmental aspects of the vehicle dealer (Fig. 3).

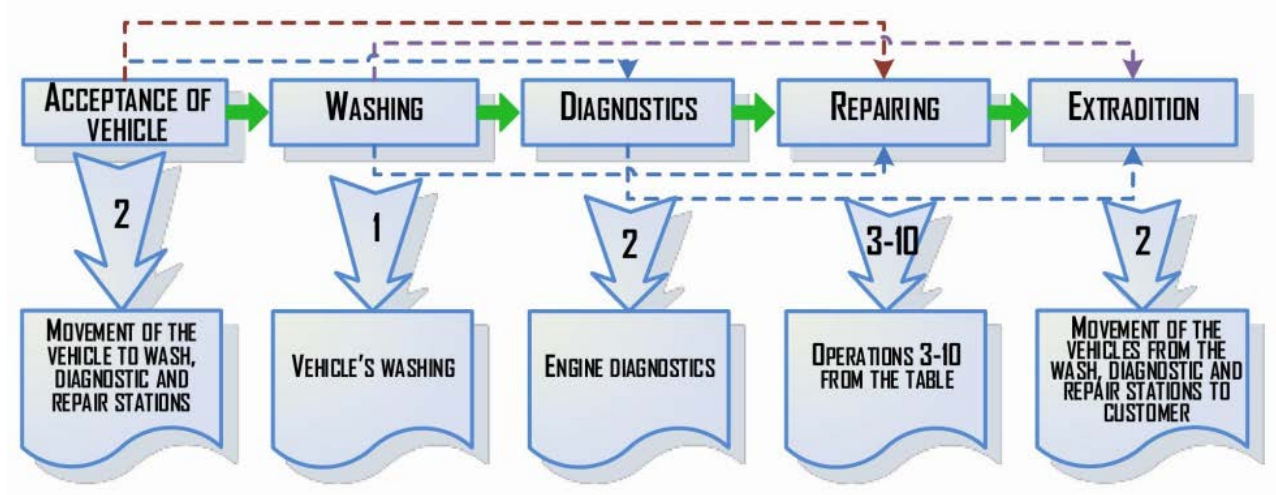

Fig. 3. Major works and operations affecting the environment.

The vehicle dealer should plan these activities in order to ensure the implementation of environmental policy through the establishment and maintenance of procedures designed for 
situations where the lack of procedures can lead to deviations from environmental policies and targeted environmental indicators. It is also advisable to define operations not only for the direct provision of vehicle-care services, but also all those that can have a negative impact on the environment, such as: loading-unloading, transportation and storage of fuels and lubricants, auto parts, etc.; acquisition, construction and reconstruction of equipment, etc.

Another way to solve the problem of negative impact of a vehicle dealer on the environment is to use scientifically based methods and models when designing a dealerservice network in order to distribute the impact on the environment evenly by improving the territorial accommodation of vehicle dealers, taking into account environmental factors [13].

The dealer-service network is a complex organizational and technical system, in the design of which the use of simulation modeling leads to the best result, since in this case the input streams are not limited to the requirements of stationarity, homogeneity, absence of aftereffect, etc., and also allows comparing different alternative versions of projects of the system, effectively monitor the experimental conditions, evaluate the operational parameters of the system [14].

The object of modeling is a territory (for example, a large city or districts), in which it is possible to allocate places for the concentration of vehicles and the location of vehicle dealers. The modeling process is proposed to begin with setting the initial parameters (determining the places of vehicle concentration, forecasting demand, determining the permissible places for locations of vehicle dealers), as well as the initial state of the dealerservice network.

\section{Results and Discussion}

The algorithm of the model for choosing the locations for the territorial accommodation of vehicle dealers is shown in Fig. 4. We take that in the first place the only vehicle dealer located in the zone of the lowest concentration of pollutants serves the whole fleet of vehicles. To determine the optimal number of repair posts of vehicle dealers, an optimization experiment is performed. Then, a simulation experiment is performed on the model to calculate network performance indicators. In the second and subsequent plans, one vehicle dealer is added to the zones of the lowest concentration of pollutants taking into account the permissible places of accommodation, and an optimization experiment is performed to determine the number of repair posts. Model performance indicators (vehicle owners' costs for vehicle delivery and waiting in the queue, number of satisfied requests, idle time of repair posts) are calculated for each plan of territorial accommodation.

The mathematical formulation of the simulation model is as follows:

$$
\left\{\begin{array}{l}
Z=Z_{1}+Z_{2} \rightarrow \min \\
\psi_{k}<\bar{\psi}_{\theta}\left(E_{1}^{k}\right)
\end{array}\right.
$$

where $Z_{1}\left(W_{p}, W_{d}, W_{w}\right)=C_{1}\left(S_{1}, W_{p}\right)+C_{2}\left(S_{2}, W_{d}, W_{w}\right)$ - the indicator reflecting the costs of the vehicle service system;

$Z_{2}\left(W_{d}, n\right)=E_{1}\left(M_{a}, n\right)+E_{2}\left(W_{d}, \vartheta, M_{m}\right)$-the indicator reflecting the environmental damage caused to the environment,

$C_{1}$ - expenses of the vehicle dealer, connected with the idle time of repair posts, $C_{1}=S_{1} \cdot W_{p}$, $S_{1}$ - the cost of the vehicle dealer when one post is idle, rubles/day, $W_{p}$ - total idle time of repair posts of the vehicle dealer, days.; 
$C_{2}$ - costs of vehicle owners associated with the delivery of cars to the vehicle dealer and waiting in the line, $C_{2}=S_{2} \cdot\left(W_{d}+W_{w}\right)$, where $S_{2}$ - average wages, rubles/days., $W_{d}$ и $W_{w}-$ the total delivery time of all vehicles to the vehicle dealer and the total waiting time for maintenance, days.;

$E_{1}$ - the amount of damage to the environment from the activities of vehicle dealers, in terms of rubles, $E_{1}=M_{a} \cdot n$, where $M_{a}$ - the amount of damage to one vehicle-arrival, rubles, $n$ - number of vehicle-arrivals [15];

$E_{2}$ - the amount of damage to the environment associated with the delivery of vehicles to the vehicle dealers, in terms of rubles, $E_{2}=W_{d} \cdot \vartheta \cdot M_{m}$, where $\vartheta$ - average speed of the vehicle, $\mathrm{km} / \mathrm{h}, M_{m}$ - the amount of damage to the environment from the movement of the vehicle by $1 \mathrm{~km}$;

$\psi_{k}<\bar{\psi}_{\theta}\left(E_{1}^{k}\right)$ - the restriction imposed on the accommodation of the vehicle dealer.

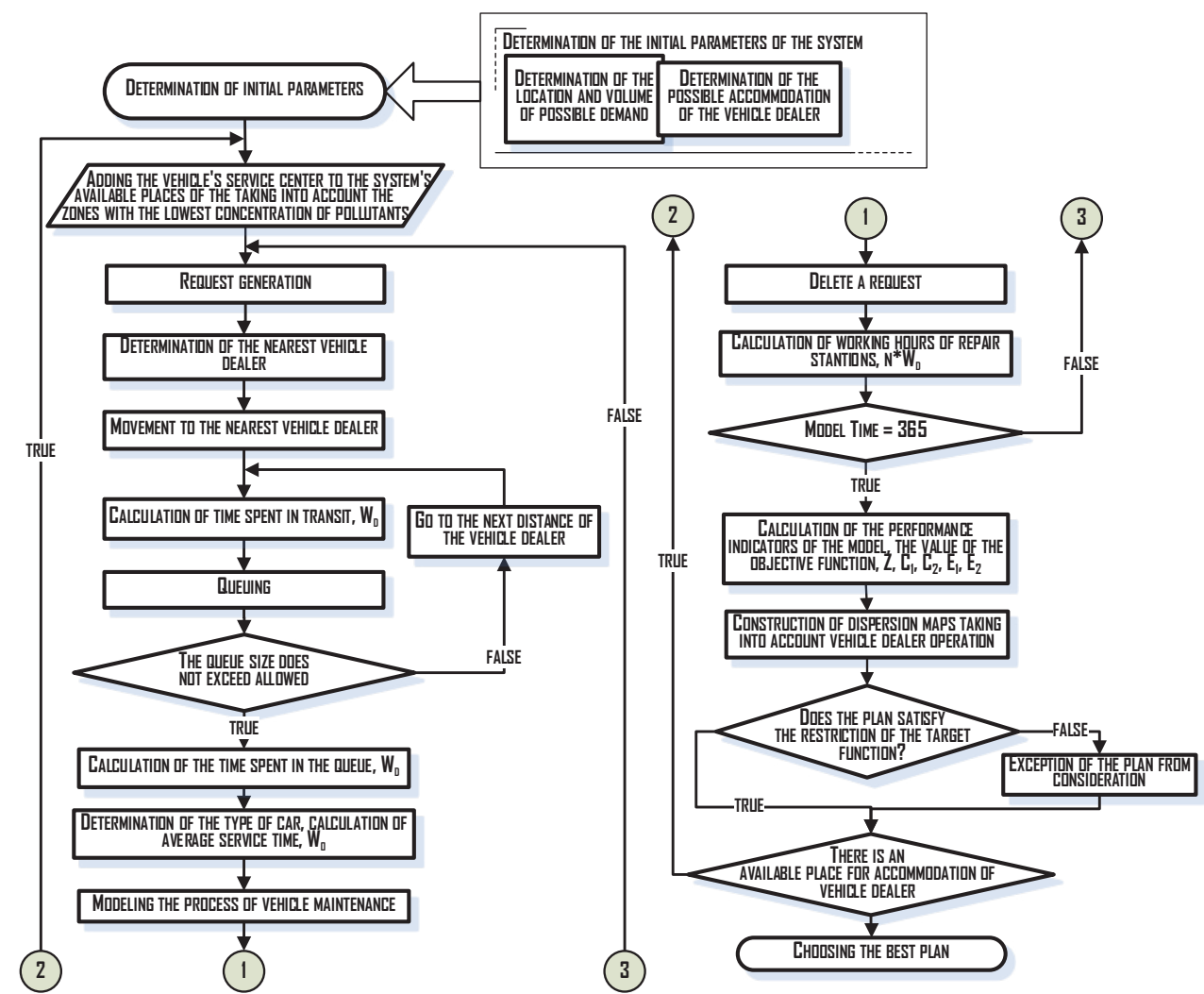

Fig. 4. Algorithm of vehicle dealers accommodation model.

\section{Conclusion}

As a result of the implementation of the developed simulation model, it is possible to find a balance between the efficiency indicators of the vehicle service network (the expenses of the vehicle dealers related to the idle time of the repair posts), the satisfaction of the clients of the vehicle dealers (the expenses of the vehicle owners for delivering cars to the dealers and waiting in line) and the negative impact on the environment. 


\section{References}

1. World Development Indicators database, World Bank, 28 April 2017.

2. $\mathrm{CO}_{2}$ time series 1990-2015 per region/country. Netherlands Environmental Assessment Agency. Retrieved 2017-03-07.

3. EEA, 2016, Air quality in Europe - 2016 report, EEA Report No 28/2016, European Environment Agency (https://www.eea.europa.eu/publications/air-quality-in-europe2016) accessed 03 September 2017.

4. State report "On the state and on the protection of the environment of the Russian Federation in 2015". Ministry of Natural Resources of Russian Federation, 2016. 639 p.

5. M. Williams, N. Arkaraprasertkul, Mobility in a global city: Making sense of Shanghai's growing automobile-dominated transport culture. Urban Studies, 54(10), pp. 2232-2248 (2017)

6. R. Khabibullin, I. Makarova, A. Pashkevich, V. Mavrin, K. Shubenkova, Application of simulation modeling to improve management of technological processes during production of automotive components. Proceedings of the 2016 17th International Conference on Mechatronics - Mechatronika, ME (2016)

7. T.G. Dedikova, M.G. Serikova, Ensuring the environmental friendliness of vehicle service enterprises (manual). International Journal of Experimental Education, 2-2, pp. 260-261 (2015)

8. New Urban Agenda. Statement of financial implications: United Nations Resolution adopted by the General Assembly on 23 December 2016; URL: http://www.un.org/en/ga/search/view_doc.asp?symbol=A/RES/71/256 (accessed 05 September 2017).

9. The Role of ICT in the Proposed Urban Sustainable Development Goal and the New Urban Agenda. United Nations Human Settlements Programme (UN-Habitat), 2015; URL: https://unhabitat.org/the-role-of-ict-in-the-proposed-urban-sustainabledevelopment-goal-and-the-new-urban-agenda/ (accessed 10 September 2017).

10. I. Makarova, V. Mavrin, K. Shubenkova, System approach to the mass production improvement. Advances in Intelligent Systems and Computing, 644, pp. 95-102 (2017)

11. S.M. Platt, I.E. Haddad, S.M. Pieber, Gasoline cars produce more carbonaceous particulate matter than modern filter-equipped diesel cars. Scientific Reports, 7(1), https://doi.org/10.1038/s41598-017-03714-9 (2017)

12. J.M. Pearce, J.T. Hanlon, Energy conservation from systematic tire pressure regulation. Energy Policy, 35(4), pp. 2673-2677 (2007)

13. International Guidelines on Urban and Territorial Planning. United Nations Human Settlements Programme (UN-Habitat), URL: https://unhabitat.org/books/internationalguidelines-on-urban-and-territorial-planning/ (2015).

14. G. D'Angelo, The simulation model partitioning problem: An adaptive solution based on self-Clustering. Simulation Modelling Practice and Theory, 70, pp. 1-20 (2017)

15. J. Filipczyk, I. Makarova, E. Belyaev, Analysis of periodical technical inspection systems in automotive transport. The experiences of Poland and Russia. Transport Problems, 10(4), pp. 121-128 (2015) 